\title{
Epidemiological and Clinical Aspects of Acne in the Dermatology Department of the Teaching Hospital of Parakou (Benin)
}

\author{
Hugues Adégbidi1 ${ }^{*}$, Christiane Koudoukpo ${ }^{2}$, Félix Atadokpèdé1, \\ Florencia do Ango-Padonou1, Hubert G. Yédomon' ${ }^{1}$ \\ ${ }^{1}$ Faculté des Sciences de la Santé de Cotonou, Université d'Abomey-Calavi, Cotonou, Bénin \\ ${ }^{2}$ Faculté de Médecine de Parakou, Université de Parakou, Parakou, Bénin \\ Email: ${ }^{\text {adegbidih@yahoo.fr }}$
}

Received 4 March 2014; revised 2 April 2014; accepted 9 April 2014

Copyright (C) 2014 by authors and Scientific Research Publishing Inc.

This work is licensed under the Creative Commons Attribution International License (CC BY).

http://creativecommons.org/licenses/by/4.0/

c) (i) Open Access

\begin{abstract}
Introduction: Acne is an affection that concerns $80 \%$ of young people in the world with a significant impact on their quality of life. The purpose of this study was to determine the epidemiological and clinical aspects of the acne in the Dermatology Department of the Teaching Hospital of Parakou (THP). Patients and Methods: We achieved a cross sectional study carrying on 167 files collected on a 20-month period in the Dermatology Department of the THP. Results: The prevalence of the acne was $31.21 \%$. Female subjects represented $69.46 \%$. Vulgaris acne was the most prevailing clinical form (47.30\%). A peak of frequency was noted in the age bracket of 21 - 25 years in the 2 sexes. The lesions were mainly located on the face $(82.63 \%)$. Some factors influencing the eruption have been evoked by the patients notably: foods, cosmetics products and stress respectively to $41.00 \%, 33.33 \%$ and $25.67 \%$. Conclusion: Our study allowed confirming the female ascendancy of acne. Besides, the adults are more represented, precisely women because of depigmenting practice. It seems in favor of an influence of the food in the intervening of the acne. Vulgaris acne was the predominant clinical form as described in literature.
\end{abstract}

\section{Keywords}

Acne, Epidemiology, Foods

\section{Introduction}

The term "acne”, in accordance with the recommendations of the terminology commission, designates follicles

\footnotetext{
"Corresponding author.
}

How to cite this paper: Adégbidi, H., et al. (2014) Epidemiological and Clinical Aspects of Acne in the Dermatology Department of the Teaching Hospital of Parakou (Benin). Journal of Cosmetics, Dermatological Sciences and Applications, 4, 129-134. http://dx.doi.org/10.4236/jcdsa.2014.43018 
damages that occur to adolescence and that are bound to the seborrhea and the formation of comedons. It is an affection that concerns $80 \%$ of young people in the world with the significant impact on their quality of life [1] [2]. Moreover a genetic predisposition, some factors seem to have a link with acne occuring as alimentation and premenstrual period. No study confirms that link nowadays but patients used to talk about them. After 12 months of work in a new dermatology department and because acne is the most frequent reason of consultation in dermatology department [3] [4], we considered this study. Its purpose was to determine the epidemiological and clinical aspects of the acne and search if there was a link between its occurrence, and food and premenstrual period in the dermatology department of the Teaching Hospital of Parakou (THP).

\section{Patients and Methods}

The study took place in the Dermatology Department of the THP. Any patient seen in consultation in the service has a medical file. This medical file includes the civil status, clinical, paraclinical, therapeutic and evolutive data. We achieved a cross sectional study carrying on 167 files collected on a 20-month period: from February 1, 2009 to September 30, 2010. The study has been made from the medical files, and concerned all patients with acne diagnosis during the period of study and after obtaining the informed consent. Acnenosological classification has been made into 4 types: vulgaris acne (Picture 1), inflammatory acne (Picture 2), nodular acne (Picture 3) formerly named nodulocystic [5] and cosmetic acne (Picture 4). The variables: sex, age, profession, the clinical variants and the location of damages have been studied. The data have been collected on a card of investigation, their treatments and analyses facts with the help of the software Ear info. The data were collected in a anonymous way and an enlightened consent was give by the patients. The medical ethic committee of the hospital gave it authorization. Chi 2 test was used for proportions comparison and a value of $p<0.05$ is statistically significative.

\section{Results}

1) Epidemiological aspects

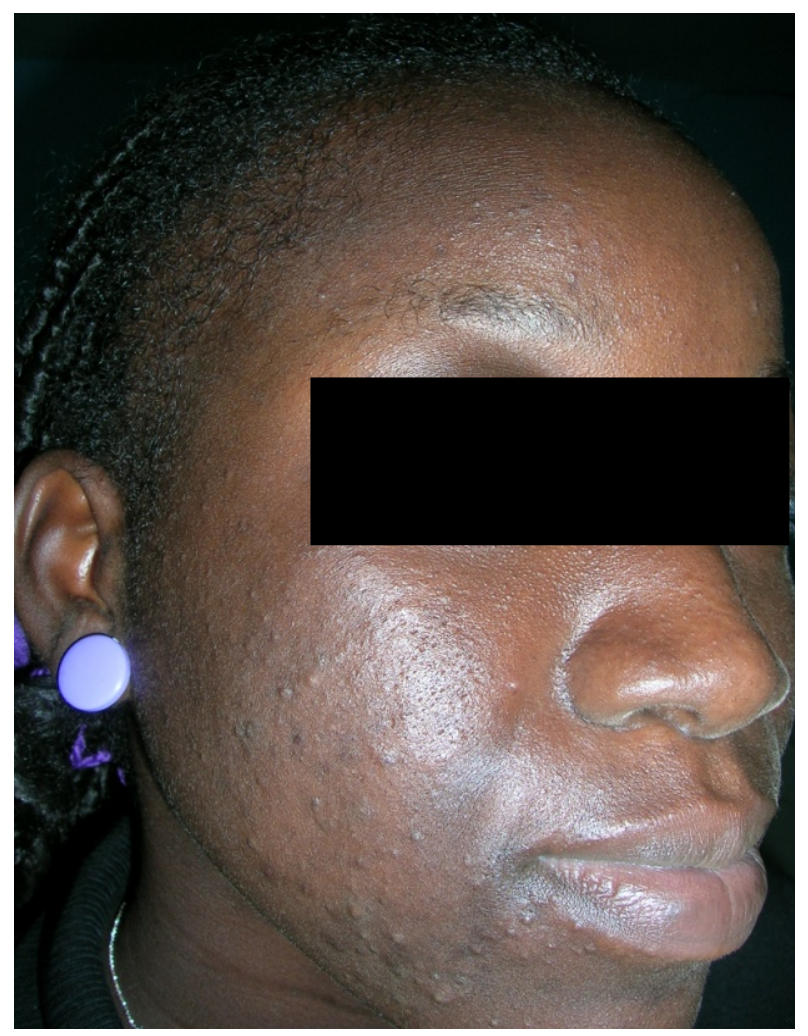

Picture 1. Vulgaris acne. 


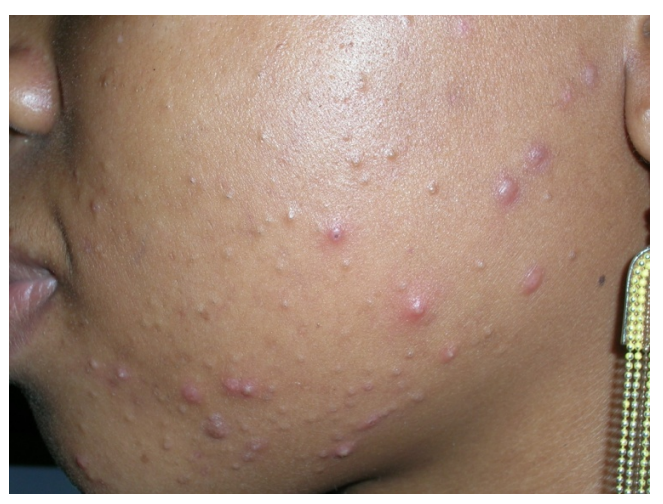

Picture 2. Inflammatory acne.

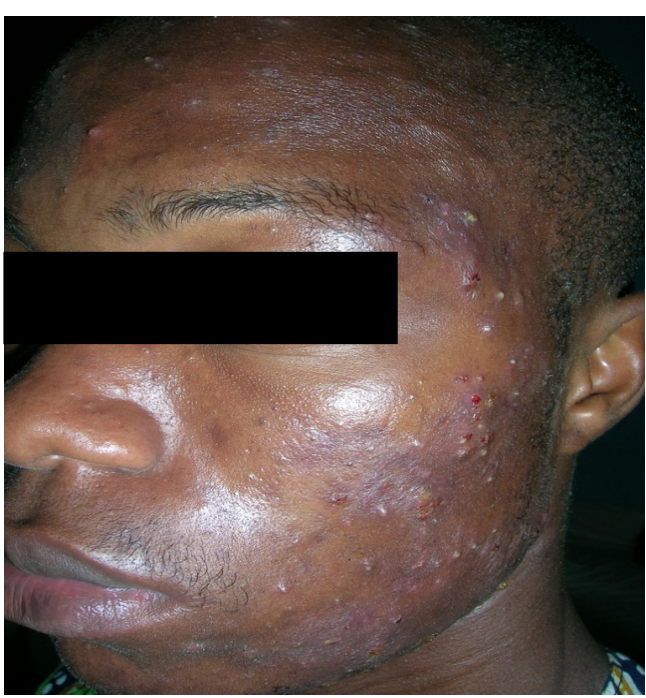

Picture 3. Nodular acne.

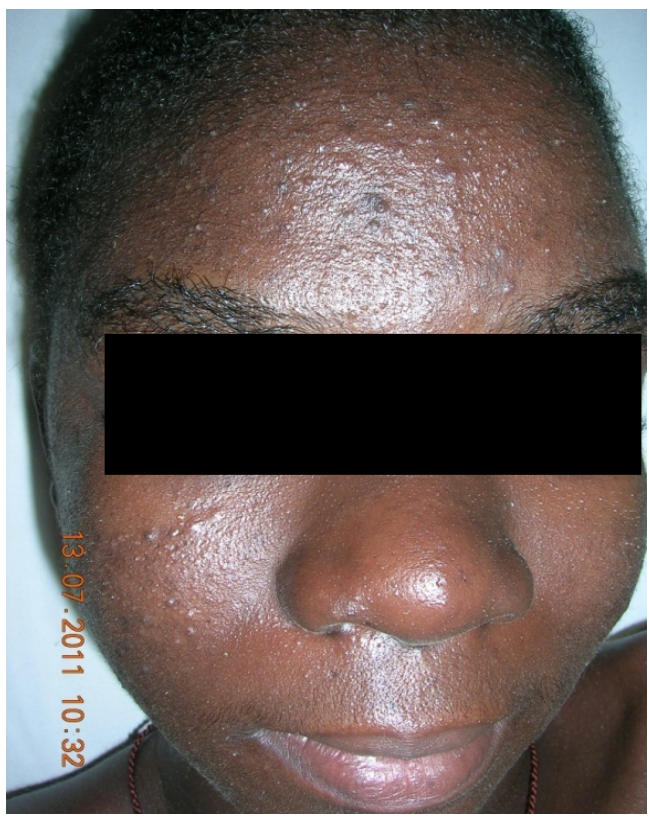

Picture 4. Cosmetical acne. 
For 535 cases of skin diseases registered during the period of study, 167 cases of acne have been kept either a prevalence of $31.21 \%$. On the 167 cases of acne registered, 116 are females (9.46\%) against 51 either (30.54\%) for males. The sex M/F ratio was therefore of 0.44 . On the 116 females, 112 were pubescent and 4 were non pubescent.

Figure 1 shows the distribution of the acne according to the sex and the age groups.

One hundred and six cases of 167 (63.47\%) had a family history of acne. The students and the pupils constituted respectively $61.68 \%$ and $19.76 \%$ of the size, and the other $18.56 \%$ were represented by teachers, secretaries, nurses, policemen, storekeepers and the craftsmen.

The notion of previous medicinal hold in the beginning of the symptoms has not been signaled at any of the patients. Some factors influencing the eruption have been evoked by the patients notably: foods, cosmetics products and stress respectively to $41.00 \%, 33.33 \%$ and $25.67 \%$. The periods have been revealed like factors coming with the regular aggravation of the acne at 93 of our 112 pubescent patients (74.11\%).

2) Clinical Aspects

a) Distribution of the acne according to clinical forms

Vulgaris acne was the most prevailing clinical form in our study (Figure 2).

b) Distribution of the acne according to the location of damages

Acne damages had distributed themselves differently on the reached location: $82.63 \%$ to the face, $22.95 \%$ to the shoulders, $17.36 \%$ to the necklines and $6.58 \%$ to the back (Table 1 ). Let's note that several locations were often reached at the same patient.

c) Distribution of the clinical forms of acne according to the location of damages.

\section{Discussion}

1) Epidemiological aspects

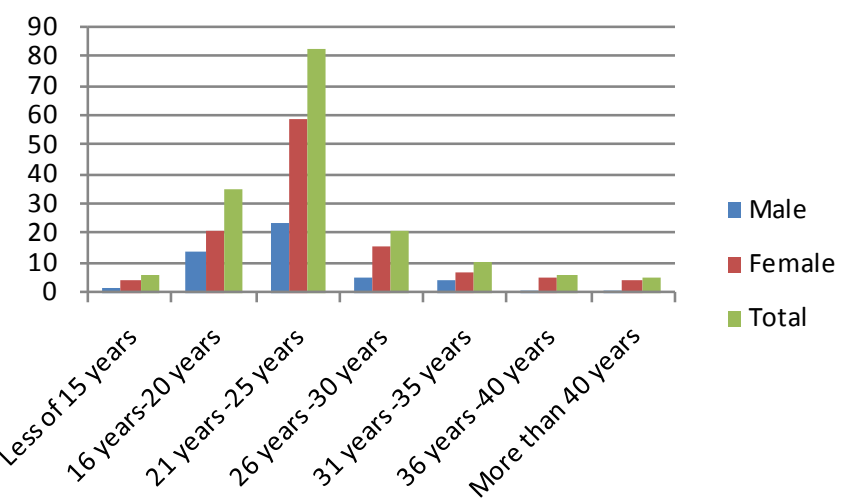

Figure 1. Distribution of the acne according to the sex and the age groups.

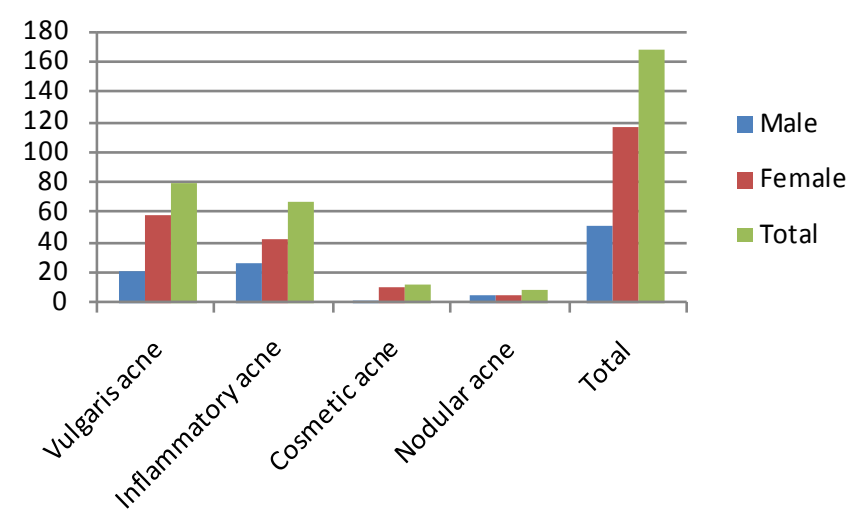

Figure 2. Distribution of the acne according the clinical forms. 
Table 1. Repartition of acne localizations.

\begin{tabular}{ccccc}
\hline Clinical forms & Face & Shoulders & Necklines & Back \\
Retentional acne & $74(53.62 \%)$ & $5(13.51 \%)$ & $10(34.48 \%)$ & $2(18.18 \%)$ \\
Infflammatory acne & $35(25.36 \%)$ & $17(45.95 \%)$ & $9(31.04 \%)$ & $6(54.55 \%)$ \\
Cosmetical ane & $18(13.05 \%)$ & $6(16.22 \%)$ & $4(13.79 \%)$ & $2(18.18 \%)$ \\
Nodular acne & $11(7.97 \%)$ & $9(24.32 \%)$ & $6(20.69 \%)$ & $1(9.09 \%)$ \\
Total & $138(100.00 \%)$ & $37(100.00 \%)$ & $29(100.00 \%)$ & $11(100.00 \%)$ \\
\hline
\end{tabular}

NB: Some patients had several localizations.

Acne constitutes the most frequent reason of consultation in dermatology department [3]. It represents 15 to $20 \%$ of the consultations [6]. In a study published in 2005 by Onayemi et al. in Nigeria [4], it represents the third reason of consultation after the infectious and allergic dermatosis. Its prevalence in our study is $31.21 \%$. It is widely superior to the one described in the literature [6] [7]. The female subjects represented $69.46 \%$ against $30.54 \%$ of male subjects in our study. Kane et al. in Senegal, then Mseddi et al. in Morocco had similar results respectively $62.43 \%$ and $75 \%$ against $37.57 \%$ and $25 \%$ [1] [3].

A peak of frequency was noted in the age bracket of 21 - 25 years in the 2 sexes. What goes against the data of the literature which gives evidence that acne disappears at the majority of subjects between 18 and 25 years [7]. This peak of frequency in this age bracket $21-25$ years is understandable on one hand by a bigger attendance of the center by this age bracket represented especially by the students and the pupils, facilitated by the closeness of the hospital with a secondary school and Parakou University; and on the other hand by the existence of some factors contributing acne eruption. The study of contributing factors showed that the food has been signaled by $41 \%$ of our patients as influencing their acne eruption, constituting the first contributing factor. The incriminated foods are: chocolate, peanut, butter, mayonnaise and milk. The use of cosmetics in particular depigmenting and fat occlusive ones was noted in $33.33 \%$ of our patients and constituted the second contributing factor after food. This use of cosmetics in particular depigmenting ones containing corticoids induces numerous dermatosis of which acne constitutes the first and third reason of consultation in dermatology according respectively to Gathse and Mahé [8] [9]. Few clinical trials were realized on the role of food in occurrence of acne. The published works are former and obligatorily lacking [10] [11]. Their results go to the sense of an absence of link between food and acne, what it is now admitted by dermatological community. A recent epidemiological study based on reviews data of the "children's nurses Heath Study II" cohort shows a correlation between the consummate quantity of milk and the presence of severe acne during the adolescence on 47,355 American women [12].

Of our 112 pubescent patients, 71.41\% experiment a regular worsening of acne in the second half of the menstrual cycle. The physiopathology of this premenstrual exacerbation is not clear but would be in connection with the physiological progestational phase [13]. Progesterone is metabolized in androsteron before it elimination during the premenstrual period.

Sixty three, forty-seven percent of our patients had a brother or a sister or their direct parents affected by acne. These results suit to those of Daniel et al. who in a comparative study found that $68 \%$ patients had a brother or a sister affected by acne against $57 \%$ without acne [14].

2) Clinical Aspects

Vulgaris acne was the most represented in our study $47.30 \%$ this suits to literature data with higher percentages going from $72.80 \%$ to $79.73 \%$ according respectively to Mseddi and Poli [3] [15]. Daniel et al. also indicated the ascendancy of vulgaris acne in metropolitan France [14]. It was more frequent in females than males in our study contrary to Daniel et al. study. In the same way inflammatory acne was more noted in females than males in Kane et al. study [1], but Daniel et al. in France [14] observed more raised about males suffering inflammatory acne than females. Nodular acne was more noted also in females than males, what does not suit to literature data reporting an ascendancy of the inflammatory forms and nodular forms in males [7]. The cosmetic acne due to fat occlusive and depigmenting creams was present in $7.19 \%$ of our patients and the greater part was female. This depigmenting practice is reported by several authors as cause of cosmetic acne [8] [9].

In our study, $82.63 \%$ of damages were located on the face. This preferential location was also reported in li- 
terature with percentages varying from $86.37 \%$ to $95.50 \%$ according to respectively Mseddi and Poli [3] [15]. This fact was also reported in literature in which acne is mainly located on face, particularly on nose, cheeks and forehead [7] [14]. In inflammatory acne, damages were also to the face but especially to the back and to the shoulders.

\section{Conclusion}

Our study allowed confirming the female ascendancy of acne. Besides, the adults are more represented, precisely women because of depigmenting practice. It seems in favor of an influence of the food in the intervening of the acne. Vulgaris acne was the predominant clinical form as described in literature.

\section{References}

[1] Kane, A., Niang, S.O., Diagne, A.C., Ly, F. and Ndiaye, B. (2007) Epidemiological, Clinical and Therapeutical Aspects of Acne at Dakar. Nouvelles Dermatolologiques, 26, 39-41.

[2] Dréno, B. (2010) What Are the News in Acne? Annales de Dermatologie et de Vénéréologie, 137, S49-S51. http://dx.doi.org/10.1016/S0151-9638(10)70024-7

[3] Mseddi, M., Abdelmaksou, D.W., Borgi, N., Elloumi, Y., Daoud, L., Souissi, A., Tutki, H. and Zahaf, A. (2005) Epidemiological and Clinical Aspects of Acne in School Children. Medecine du Magreb. No. 124, 53-55.

[4] Onayemi, O., Isezu, S.A. and Njoku, C.H. (2005) Prevalence of Different Skin Conditions in an out Patients' Setting in North. Western Nigeria. International Journal of Dermatology, 44, 7-11. http://dx.doi.org/10.1111/j.1365-4632.2004.02298.x

[5] Humbert, P. (2003) Severe Forms of Acne. Annales de Dermatologie et de Vénéréologie, 130, 117-120.

[6] Auffret, N. (2003) What Are the News in Acne Physiopathology? Annales de Dermatologie et de Vénéréologie, 130, 101-106.

[7] Revuz, J. (2003) Youngest Polymorphic Acne and Adult Acne. Annales de Dermatologie et de Vénéréologie, 130, 113-116.

[8] Gathse, A., Obengui and Ibara, J.R. (2005) Motifs of Consultation Linked to Bleaching in 104 Women at Brazzaville, Congo. Bulletin de la Société de Pathologie Exotique, 98, 387-389.

[9] Mahé, A., Kéita, S. and Bobin, P. (1994) Dermatological Complications of the Using of Bleaching Products at Bamako (Mali). Annales de Dermatologie et de Vénéréologie, 121, 46-51.

[10] Magin, P., Pond, D., Smith, W. and Watson, A. (2005) A Systematic Review of the Evidence for "Myths and Misconceptions” in Acne Management Diet Face-Washing and Sunlight. Family Practice, 22, 62-70. http://dx.doi.org/10.1093/fampra/cmh715

[11] Puzenat, E., Riou-Gotta, M.O., Messick, R. and Humbert, P. (2010) Facial Dermatosis: Acne, Rosacea, Seborrhoeic Dermatitis. Revue du Praticien, 60, 849-755.

[12] Adebamowo, C.A., Spiegelman, D., Danby, W., Frazier, L., Wiellett, W.C. and Holmes, M.D. (2005) High School Dietary Dairy Intake and Teenage Acne. Journal of the American Academy of Dermatology, 52, 207-214. http://dx.doi.org/10.1016/j.jaad.2004.08.007

[13] Stoll, S., Shalita, A.R., Webster, G.F., Kaplan, R., Danesh, S. and Penstein, A. (2001) The Effect of the Menstrual Cycle on Acne. Journal of the American Academy of Dermatology, 45, 957-960. http://dx.doi.org/10.1067/mjd.2001.117382

[14] Daniel, F., Dreno, B., Poli, F., Auffret, N., Beylot, C., Bodokh, I., et al. (2000) Descriptive Epidemiology of Acne in Metropolitan France School Children in Autumn 1996. Annales de Dermatologie et de Vénéréologie, 127, $273-278$.

[15] Poli, F., Dreno, B. and Verschoore, M. (2001) An Epidemiological Study of Acne in Female Adults: Results of a Survey Conducted in France. Journal of the European Academy of Dermatology and Venereology, 15, 541-546. http://dx.doi.org/10.1046/j.1468-3083.2001.00357.x 